\title{
Relation between leptin and the regulation of glucose metabolism
}

\author{
G. Frühbeck, J.Salvador \\ Department of Endocrinology, University Clinic, University of Navarra, Pamplona, Spain
}

Keywords Leptin, $o b$ gene, insulin, glucagon, cholecystokinin, glucose homeostasis, obesity, satiety.

\section{Overview}

The identification of the $o b$ gene through positional cloning [1] and the discovery that its encoded protein, leptin, is essential for body weight homeostasis [2-4] have permanently altered the field of metabolic physiology. Over a 5-year period a substantial and rapidly changing body of knowledge has been created.

Leptin, a $16 \mathrm{kDa}$ circulating hormone produced and released primarily by adipocytes, exerts a regulatory control on food intake and energy expenditure [2-4]. Plasma leptin concentrations are correlated with total fat mass, per cent body fat and body mass index acting as a sensing hormone or "lipostat" in a negative feedback control from adipose tissue to the hypothalamus, the brain centre responsible for satiety $[5,6]$. Thus, leptin informs the brain about the abundance of body fat, thereby allowing feeding behaviour, metabolism and endocrine physiology to be coupled to the nutritional state of the organism. Leptin-deficient $o b / o b$ mice exogenously treated with leptin have a pronounced body weight loss with a distinct loss of discernible body fat [2-4]. This effect is not only attributable to a decreased food intake but

Corresponding author: G. Frühbeck, R Nutr MD PhD, Dept. of Endocrinology, Clínica Universitaria de Navarra, Avda. Pío XII 36, 31008-Pamplona, Spain

Abbreviations: OB-R, Leptin receptors; CNS, central nervous system; STAT, signal transducer and activator of transcription; GLP-1, glucagon-like peptide 1; PI3, phosphatidylinositol-3; NEFA, non-esterified fatty acids; UCP, uncoupling proteins; PEPCK, phosphoenolpyruvate carboxykinase; ICV, intracerebroventricular; IRS, insulin-receptor substrate; GLUT, glucose transport. also to an increased basal metabolic rate with selective promotion of fat metabolism [2,7-10].

Leptin was discovered through a very specific biological action consisting in its involvement in body weight and appetite regulation. Interestingly, leptin has structural similarities to the family of helical cytokines [11]. Many cytokines, originally isolated through particular biological actions, have subsequently been shown to be capable of stimulating a variety of biological responses in a wide spectrum of cell types. Thus, leptin shares with other cytokines an extreme functional pleiotropy and has been shown to be involved in quite diverse physiological functions, such as reproduction [12], angiogenesis [13], haematopoiesis [14] and immune responsiveness [15].

Consistent with leptin's role in controlling appetite and energy metabolism, leptin receptors (OB-R) have been found in the hypothalamus and adjacent brain regions $[16,17]$. At the beginning direct leptin actions were thought to be exclusively confined to the central nervous system (CNS). The almost ubiquitous distribution of functional OB-R provides, however, evidence for a multiplicity of peripheral target organs. At the cellular level OB-R, structurally related to the family of cytokine receptors, have been found to activate Janus kinases and to function as a signal transducer and activator of transcription (STAT) pathways [16]. Special attention among the extraneural tissues expressing functional OB-R should be given to organs involved in metabolism and digestion like the pancreas, skeletal muscle and the gastrointestinal system [16,17]. The pancreas has evolved a complex and exquisitely sensitive mechanism for matching the stimulation or inhibition of pancreatic hormone release to the prevailing metabolic needs [18]. Pancreatic endocrine and exocrine secretion is released in response to nutrient inflow from the gut and to gastrointestinal secretagogues. Even though the insulo-acinar axis has been exten- 


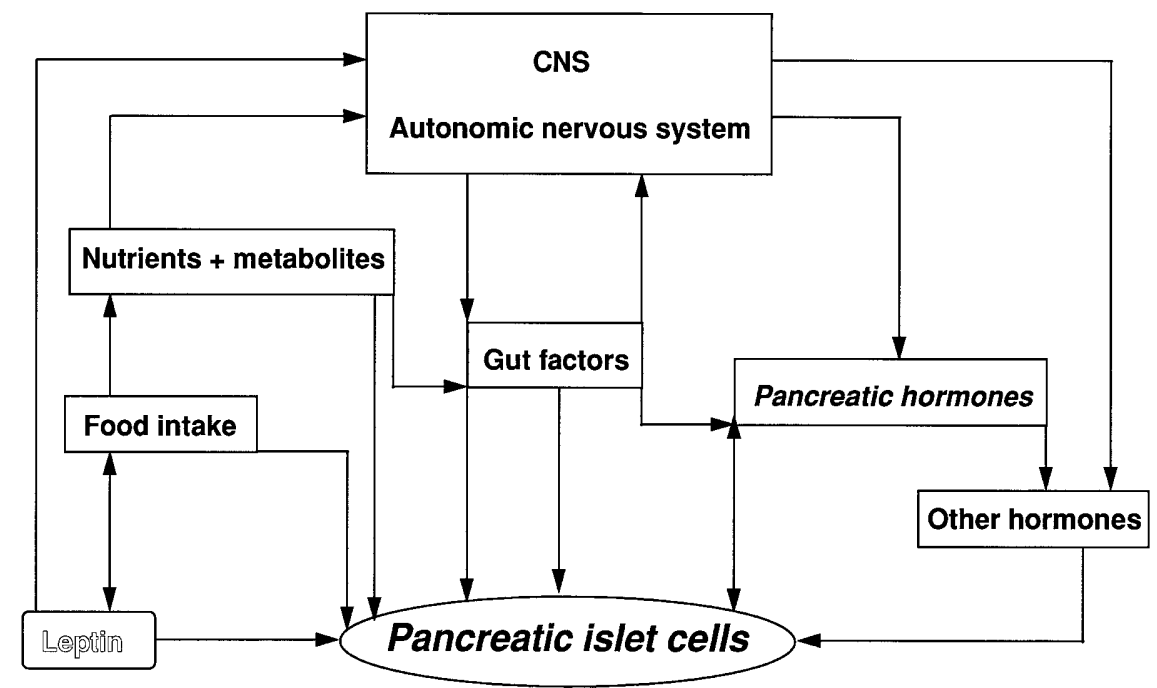

Fig. 1. Proposed model of the interrelations between nutritional, neural and hormonal factors working together on pancreatic islet cells

sively studied, the mechanisms of the regulation of pancreatic secretion have not been fully assessed. In this review the complex relation between leptin and insulin in the regulation of glucose metabolism is discussed in the broader perspective of integrative physiology (Fig. 1).

Leptin inhibits food intake, reduces body weight, stimulates energy expenditure and decreases hyperglycaemia and hyperinsulinaemia in obese rodents [2-4]. It was also observed that changes in glycaemia precede changes in body weight [2]. In addition, pair-feeding studies [7] and experimental hyperleptinaemic animal models $[19,20]$ provide compelling evidence that leptin exerts an appreciable metabolic regulatory role, in addition to appetite suppression. It has been shown that leptin is involved in the regulation of glucose transport [21, 22]. The importance of glucose transport as the rate-limiting step in whole body glucose utilization becomes more important in metabolic disease states such as obesity and Type II (non-insulin-dependent) diabetes mellitus, in which insulin-mediated glucose transport is impaired. Although leptin has been shown to increase whole body glucose utilization, the effect of leptin on glucose at the tissue level remains controversial.

\section{Leptin action on pancreatic islets}

Plasma glucose concentration is tightly controlled throughout life under physiological conditions. This precise control is best seen during periods of food deprivation or consumption. The stability of the plasma glucose concentration is a reflection of the bal- ance between the rates of whole body glucose production and utilization. Each of these processes is tightly regulated by the concentrations of hormones and substrates in blood. Functional OB-R have been shown to be expressed in pancreatic islets [23, 24]. This points to the possibility of leptin involvement in local metabolic regulation. In this context, researchers have evaluated the possible physiological role of leptin on the endocrine pancreas.

Leptin action on insulin production and release. The relation between leptin and insulin seems to be complex. Some researchers failed to show a direct effect of leptin on the release of either insulin or glucagon in the isolated perfused rat pancreas [25]. Other studies provide, however, evidence that leptin can directly inhibit both basal and glucose-stimulated insulin secretion [23, 24]. As depicted in Figure 2, leptin inhibits insulin secretion by acting on ATP-sensitive potassium channels $[26,27]$, a mechanism later reported to mediate leptin action in the hypothalamus [28]. The inhibitory effect of leptin on insulin secretion does not seem to be due to major actions on the main glucose-phosphorylating pathways in the beta cells as no changes in hexokinase and glucokinase activities have been observed [29] and glucokinase regulation appears to be leptin-independent [30]. Arginine-induced insulin production did not seem to be affected by leptin in vitro [29] suggesting that, at least some of the mechanisms through which amino acids induce insulin release are not influenced by leptin. A possible participation of leptin in amino acid-stimulated insulin production under physiological circumstances cannot, however, be ruled out.

Leptin has been shown to specifically target the phospholipase $\mathrm{C}$ /protein kinase $\mathrm{C}$-mediated regulatory component of insulin secretion rather than the glucose or protein kinase A signalling components of the secretory process [31]. Leptin constrained the enhanced phospholipase C-mediated insulin secre- 
tion characteristic of islets from $o b / o b$ mice, without influencing release from islets of lean mice. A specific enhancement in phospholipase C-mediated insulin secretion is the earliest reported developmental alteration in insulin secretion from islets of $o b / o b$ mice and thus a logical target for leptin action. This effect of leptin on phospholipase C-mediated insulin secretion has been reported to be dose-dependent, rapid in onset (within about $3 \mathrm{~min}$ ) and reversible [31]. Leptin was equally effective in constraining the enhanced insulin release from islets of $o b / o b$ mice caused by protein kinase $\mathrm{C}$ activation, a downstream mediator of the phospholipase $\mathrm{C}$ signalling pathway. Therefore, one function of leptin in body composition control could be to target a protein kinase C-regulated component of the phospholipase C/protein kinase $\mathrm{C}$ signalling system within islets to prevent hypersecretion of insulin [31].

It has also been reported that leptin at physiological concentrations suppresses the second phase of insulin secretion, at least in part, through an inhibitory effect on the $\mathrm{Ca}^{2+}$-dependent protein kinase $\mathrm{C}$ isoform [32]. Additionally, inhibition of insulin secretion and preproinsulin mRNA expression by leptin has been described by several groups [23, 32-38]. By examining the regulatory mechanisms governing gene expression in the pancreatic beta cell line INS-1 and $o b / o b$ islets evidence was provided that leptin reduces the transcriptional activity of the rat I gene promoter and alters binding of distinct proteins, including STAT5b complexes to upstream sequences within the 5'-promoter region of the rat insulin gene [39]. Leptin, therefore, exerts inhibitory effects on both insulin secretion and insulin gene expression in beta cells, but by different cellular mechanisms.

Differential effects of leptin in beta cells at low and high doses have been reported [38]. Notably, in rodent pancreatic beta cells, leptin can exert differential effects on ATP-sensitive potassium channels and preproinsulin gene regulation in the presence of the insulinotropic hormone, glucagon-like peptide 1 (GLP-1). Whereas evidence has been provided that GLP-1 can override short-term inhibition of insulin secretion by leptin mediated through activation of ATP-sensitive potassium channels [27], the same is not observed for the inhibitory regulation of preproinsulin gene expression by leptin [39]. At normal glucose concentrations preproinsulin gene expression in INS-1 cells is only inhibited by leptin when concomitantly stimulated by GLP-1. This could indicate that leptin signalling from the adipose tissue as part of an adipo-insular axis does not interfere with the well-established entero-insular axis, which in the short-term increases postprandial insulin secretion by GLP-1. On the other hand, leptin can under certain conditions also be able to counteract GLP-1 stimulated insulin secretion, as has been reported for the perfused rat pancreas [40] and in mice postprandially [35].
The existence of a direct suppressive effect of leptin on insulin production at the level of both stimulus-secretion coupling and gene expression as well as the antagonism between leptin and GLP-1 signalling on beta cells have been further shown in human islets [41]. These findings support the leptin-related effectors of insulin secretion operating in rodents being equivalent to those in humans.

Furthermore, leptin could inhibit long-term stimulation of preproinsulin gene expression during the fasting state. The inhibitory actions of leptin on preproinsulin gene expression appear to be transmitted through an intracellular signalling pathway that differs from the one affecting ATP-sensitive potassium channels and with different sensitivity to ambient glucose concentrations [39]. Whereas short-term inhibition of insulin secretion by leptin has been recently proposed to be mediated through phosphatidylinositol 3 (PI3)-kinase-dependent activation of cyclic nucleotide phosphodiesterase $3 \mathrm{~B}$ and subsequent suppression of cAMP concentrations [38], the regulatory effects of leptin on transcription of the preproinsulin gene in pancreatic beta cells could be transmitted directly by means of the Janus kinases and STAT signalling cascades [39]. It is tempting to speculate that leptin serves as an inhibitory control signal provided by adipose tissue to prevent extended stimulation of preproinsulin gene expression in beta cells by incretins and glucose and to prevent sustained overproduction of insulin and hyperinsulinaemia.

Assuming the mechanisms of leptin actions in human and rodent islets are similar to actions in the hypothalamus, chronic hyperleptinaemia could desensitize leptin reception in the pancreatic beta cells in susceptible obese patients, which could hypothetically lead to increased preproinsulin gene expression, enhanced insulin biosynthesis and eventually hyperinsulinaemia. Whether transcriptional dysregulation of the preproinsulin gene is, however, involved in the development of obesity and adipogenic diabetes mellitus in vivo requires further research.

Leptin seems to be implicated in controlling insulin release by increasingly inhibiting insulin expression as adipose mass enlarges and the anabolic effect of insulin on the adipose tissue is undesirable. Moreover, leptin has been shown to alter the mRNA of genes encoding enzymes of non-esterified fatty acid (NEFA) metabolism and uncoupling proteins (UCP)-2 in pancreatic islets [42, 43]. Chronic hyperleptinaemia, induced by adenoviral transfer of leptin cDNA, reduced acetyl CoA carboxylase and fatty acid synthetase mRNA in islets of wild-type control rats by $93 \%$ and $80 \%$, respectively but did not decrease the high expression of these lipogenic enzymes in islets of falfa rats [43]. Furthermore, recombinant leptin cultured with islets isolated from wild-type rats lowered acetyl CoA carboxylase and fatty acid synthetase expression by $66 \%$ and $47 \%$, respectively 


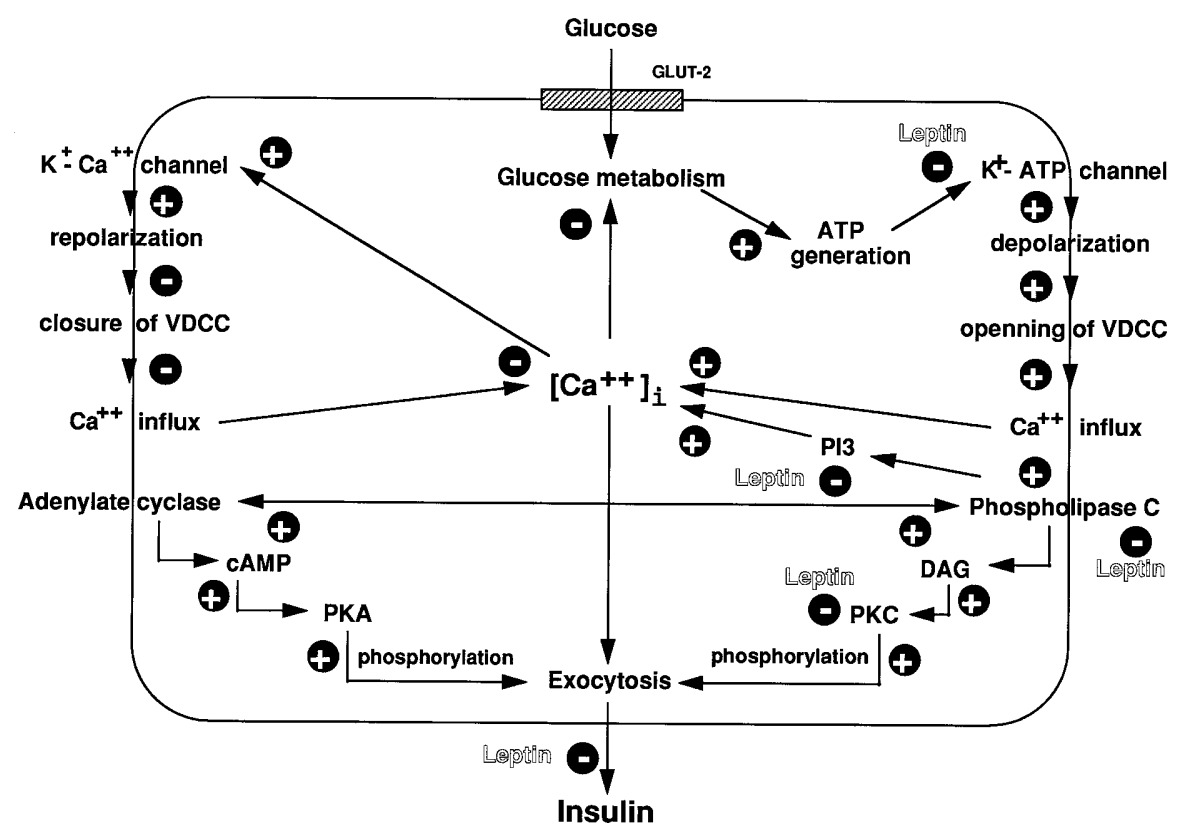

Fig. 2. Diagram of the postulated molecular mechanisms influenced by leptin in the pancreatic beta cell. VDCC, voltage-dependent $\mathrm{Ca}^{2+}$ channels; PKA, protein kinase A; DAG, diacylglycerol; PKC, protein kinase C

but had no effect in $f a / f a$ islets [43]. Thus, de novo lipogenesis in islets seems to be controlled by leptin and remains low in leptin-responsive islets whereas it is increased in leptin-insensitive $f a / f a$ islets, contributing to the fat overload that leads to beta-cell dysfunction and diabetes. Consequently, enhanced de novo lipogenesis in leptin-unresponsive humans could have a key role in the pathogenesis of lipotoxic diabetes.

Islet blood flow. An adequate islet blood perfusion is pivotal both for oxygen and nutrient supply of the endocrine cells and for dispersal of islet hormones to target organs [44]. This is of particular importance when an increased requirement of insulin is imposed on the beta cells. Thus, most conditions associated with increased insulin secretion are initially accompanied by an augmented islet blood flow. Hyperglycaemic, hyperinsulinaemic, obese, one-month-old $o b / o b$ mice showed an increased islet blood flow compared with age-matched lean animals. Notably, the augmented blood flow could be abolished by pretreatment with leptin [45]. It has been suggested therefore that the initial increase in islet blood flow in obese mice is due to the leptin deficiency. Notably, when blood flow is corrected for differences in islet volume, a $50 \%$ decrease in islet blood flow has been observed in adult obese mice despite their hyperinsulinaemic state compared with age-matched lean mice [46]. Therefore, the changes described in islet blood flow could be of physiological relevance in the impairment of islet function in obesity and diabetes mellitus.

\section{Leptin action on liver}

It has become increasingly evident that leptin has an important role in the regulation of carbohydrate and lipid metabolism. Rapid elevations in plasma leptin concentrations have been shown to modulate hepatic gene expression of the gluconeogenic enzyme phosphoenolpyruvate carboxykinase (PEPCK) and the rate of gluconeogenesis [47]. Leptin induces a redistribution of intrahepatic glucose fluxes and enzymatic changes that closely resemble those of fasting. All these metabolic effects of leptin seem to be mainly mediated through its action on hypothalamic OB-R as short-term intracerebroventricular (ICV) leptin treatment largely reproduced the effect on hepatic glucose fluxes of leptin given systemically at much higher doses [48].

In studies of postabsorptive gluconeogenesis using 20-h fasted rats, leptin stimulated the rate of hepatic glucose production (Fig. 3), which was accounted for by increased lactate uptake and can therefore be interpreted as lactate-induced gluconeogenesis [49]. Insulin and leptin reduced, but did not completely block, epinephrine-stimulated glycogenolysis. Simultaneous infusion of insulin and leptin did not, however, additively inhibit epineprine-induced hepatic glycogenolysis [49]. In this respect, it can be speculated that leptin and insulin share certain steps of the postreceptor activation cascades. Regarding OB-R activation in the liver, leptin is known to have an insulinlike effect by increasing PI-3 recruitment to insulinreceptor substrate (IRS)-1 in HepG2 cells [50] and to IRS-2 in H-35(OB-R) clones [51]. Furthermore, 
leptin has been shown to stimulate mitogen-activated protein kinase, which is also involved in insulin transduction [52]. In contrast to the reduction in epinephrine-stimulated glucose output, lactate production rates remained raised in the presence of either insulin or leptin [49]. This finding could be explained by a compensatory increase of glycolysis in response to hypoxia resulting from $\alpha$-adrenergic vasoconstriction, which is reflected by an increased portal pressure during epinephrine exposure.

The partial inhibition of glycogenolysis reported using isolated liver perfusion [49] probably leads to preservation of hepatic glycogen stores. In contrast, either intravenous or ICV leptin infusion for $5 \mathrm{~h}$ in lean mice have been reported to decrease liver glycogen concentrations by around $35 \%$ [53]. This apparent inconsistency could be explained by differences in the hormonal milieu between the experimental settings. In this sense, metabolic conditions of increased hepatic glycogen turnover could have been created during leptin exposure compared with control [53] due to the lower insulin:glucagon ratio [54]. Hyperinsulinaemic euglycaemic clamps yielded an almost $50 \%$ inhibition of endogenous glucose production by suppression of glycogenolysis after a 6-h leptin infusion in rats [47]. Similar findings were also obtained in experiments at higher leptin concentrations [49]. In the postabsorptive state the increase observed in the gluconeogenic rate by glucagon and leptin was more pronounced after 60 to 90 min of liver perfusion and accompanied by an increase in lactate uptake [49]. In addition, a contribution of renal glucose production to whole-body glucose production should not be completely ruled out.

The metabolic effects of leptin on the liver are likely to neutralize or diminish the compensatory mechanisms which normally favour regaining normal body weight after fasting or food restriction. Because the net flux through glycolysis/gluconeogenesis determines the hepatic concentration of malonyl-CoA, the effects of leptin on PEPCK and gluconeogenesis are likely to limit the hepatic formation of triglycerides by favouring NEFA entry to the mitochondria and their $\beta$-oxidation $[9,47]$. Although the liver is the principal site for de novo lipogenesis in humans, leptin has also been shown to promote lipid oxidation and decrease tissue triglycerides at other tissue sites $[9,55-58]$. These effects of leptin on lipid metabolism, which are probably mediated by diverse molecular and biochemical events in various tissues, could contribute to the beneficial influence of long-term leptin treatment on hepatic and peripheral insulin action [2, 59-61]. A study attempting to approximate physiological conditions by using a constant ICV infusion together with low leptin doses rather than a bolus injection and high concentrations of the OB protein did not show a statistically significant increase in either basal or insulin-stimulated rates of glucose disposal [48]. Conversely, in mice parallel increases in both glucose production and disposal $5 \mathrm{~h}$ after ICV leptin treatment have been reported [53]. Because the effects on glucose metabolism were observed without changes in plasma glucose and insulin concentrations, it has been suggested that leptin activated efferent signals from the CNS to the liver and peripheral tissues [53]. Thus, it seems plausible that the stimulatory effect of ICV leptin on peripheral glucose uptake requires high peak concentrations of leptin at cerebral sites. Regardless of the differences between the diverse methodological approaches, experiments have unveiled the effects of leptin on glucose fluxes and that there are redundant central and local actions of leptin on the liver should not be ruled out.

In a recent study the effect of leptin given intravenously to $o b / o b$ mice for $6 \mathrm{~h}$ was reported [62]. Leptin stimulated hepatic glucose production, which was associated with increased glucose-6-phosphatase activity. Conversely, PEPCK activity was diminished. Notably, hepatic IRS-1-associated PI3-kinase activity was slightly increased but neither the content of glucose transport (GLUT)2 nor the phosphorylation state of the insulin receptor and IRS- 1 were changed [62]. These findings suggest that leptin effects on glucose metabolism differ between lean mice and hyperglycaemic, hyperinsulinaemic obese animals.

Notably, certain metabolic defects found in $d b / d b$ mice and $f a / f a$ rats, which are leptin-resistant due to a mutation in the $O B-R$ gene, can now be explained, at least in part, by impaired leptin action at the hepatic level [49]. Hepatic glucose production has been reported to be increased in falfa rats [63]. Furthermore, in hepatocytes isolated from $\mathrm{fa} / \mathrm{fa}$ rats basal lactate/ pyruvate-dependent gluconeogenesis has been shown to be reduced by approximately $60 \%$ compared with lean animals [64]. This finding was associated with increased activities of glycolytic enzymes like glucokinase and pyruvate kinase and decreased activities of gluconeogenic enzymes like glucose-6-phosphatase and PEPCK. These enzymatic changes promote triglyceride synthesis and simultaneously decrease gluconeogenesis in this model of leptin resistance. The stimulation of triglyceride synthesis proposed as happening in leptin-resistant rats is further supported by the $13 \%$ reduction in liver triglyceride concentrations observed in a hyperleptinaemic, but not leptinresistant, rat model [9]. The apparent paradoxical absence of increased plasma NEFA concentrations could be explained by an effect of leptin to primarily limit hepatic triglyceride accumulation or to promote intrahepatic NEFA oxidation or both, which in turn might favour gluconeogenesis [65].

Leptin seems to directly affect hepatic glucose metabolism through an insulin-mimicking effect on glycogenolysis and a glucagon-like effect on gluconeogenesis. It is conceivable that leptin is involved in switching hepatic substrate oxidation from carbohy- 
drates to lipids and participates in the control of liver glycogen stores in obesity. In obese patients, endogenous glucose production is not increased despite augmented gluconeogenesis [66], which implies simultaneous suppression of hepatic glycogenolysis. Thus, increased plasma leptin concentrations could help to suppress hepatic glycogen turnover and to thereby initially maintain euglycaemia in obesity.

\section{Leptin action on gut}

The small intestine has the ability to adjust its absorptive function by integrating multiple regulatory influences including neurotransmitters, hormones and local mediators. Multiple short isoforms of the OB-R are expressed throughout the gastrointestinal tract in relation with a potential role of leptin in nutrient absorption [67]. The functional OB- $\mathrm{R}$ is predominantly expressed in the jejunum and more weakly in the ileum, the two major sites that are involved in nutrient handling. In this context, it has been shown that leptin produced a rapid inhibitory effect on sugar absorption in rat intestinal rings [68]. Likewise, leptin causes a rapid activation of STAT5 in jejunum, which is associated with a reduction of the apolipoproteinAIV transcript expression 90 min after ingestion of a pure fat load [67]. Under physiological conditions, postprandial rises in plasma leptin could function as a buffer system to reduce the plasma chylomicron triglyceride concentrations by reducing apolipoprotein-AIV. It is possible that leptin serves as a tonic inhibitory mechanism on the apolipoprotein-AIV system to reduce the concentrations of secreted triglycerides. Leptin has been shown to induce enzymes of fatty acid oxidation [42] and thus might promote a switch in fuel metabolism to ß-oxidation of fatty acids. This could account for a reduction in apolipoprotein-AIV mRNA at the transcriptional or post-transcriptional level.

Recently, the stomach has also turned out to be a source of leptin [69], in addition to adipocytes and placenta. Leptin expression seems to be localized in the chief cells in the lower half of the fundic glands. When rats were fasted for $18 \mathrm{~h}$ the amount of gastric leptin slightly decreased. In contrast, plasma leptin concentrations are known to decline sharply during fasting [70]. Treating these fasted animals with cholecystokinin produced a dose-dependent decrease in the leptin content of the fundic epithelium whereas the plasma leptin concentration increased rapidly [69]. The effect of cholecystokinin on leptin reached maximum within $15 \mathrm{~min}$. The changes observed in gastric leptin during refeeding probably reflected leptin neosynthesis. These observations indicate that the rapid increase observed in plasma leptin concentrations in response to cholecystokinin involves the mobilization of the gastric leptin store [69]. The increase in plasma leptin concentration was relatively small and, therefore, unlikely to have any large, direct effect on satiety control. It is, however, in agreement with the reported synergistic interaction of leptin with cholecystokinin [71-73], the involvement of leptin in early cholecystokinin-mediated effects on satiety $[74,75]$ and the local action on vagal afferent terminals of the stomach [76]. Simultaneously, gastric leptin could enter the liver and influence glucose production and uptake as well as hepatic expression of genes encoding key metabolic enzymes.

\section{Leptin action on skeletal muscle}

Skeletal muscle is the quantitatively most important target tissue for insulin in glucose metabolism. Thus, muscle tissue has a central role in insulin action and in the pathogenesis of insulin resistance associated with obesity.

Studies of leptin's effects on glucose metabolism have typically been confounded by the weight-reducing actions of leptin treatment, which by themselves could affect glucose homeostasis. Circumventing this possibility by in vivo experiments with short-term intravenous and ICV leptin infusions showed rapid effects on glucose metabolism. A statistically significant increase in glucose turnover and glucose uptake, independent of increased plasma insulin were obtained [53]. Leptin-stimulated glucose uptake was decreased in denervated hindlimb in both extensor digitorum longus and soleus relative to innervated muscles. Thus, the effects of leptin on glucose metabolism in skeletal muscle were suggested to be mediated, in part, by the CNS. The residual increase in glucose uptake by denervated soleus in mice treated intravenously with leptin compared with controls receiving vehicle was attributed to hormonal factors such as higher concentrations of triiodothyronine. Other studies provide, however, evidence that independent of either hormonal or centrally mediated influences, leptin could directly modulate muscular glucose handling [21, 22, 57, 58, 77-79].

The mechanisms by which leptin stimulates glucose uptake are still to be fully explained. There is evidence for a crosstalk between leptin and the insulin intracellular signalling pathways [80, 81]. Leptin seems to mimic the effects of insulin on glucose transport and glycogen synthesis through a PI3-kinase-dependent pathway. In $\mathrm{C}_{2} \mathrm{C}_{12}$ myotubes leptin has been shown to activate Janus kinase 2, which induces tyrosine phosphorylation of IRS-2 leading to activation of PI3-kinase. This effect of leptin occurs independently of IRS-1 activation. In skeletal muscle, the insulin effect on glucose uptake is mainly mediated by GLUT4 translocation. A central role of PI3-kinase, both in the signalling to GLUT4 translocation and glycogen synthesis, has been shown [82]. This is in ac- 


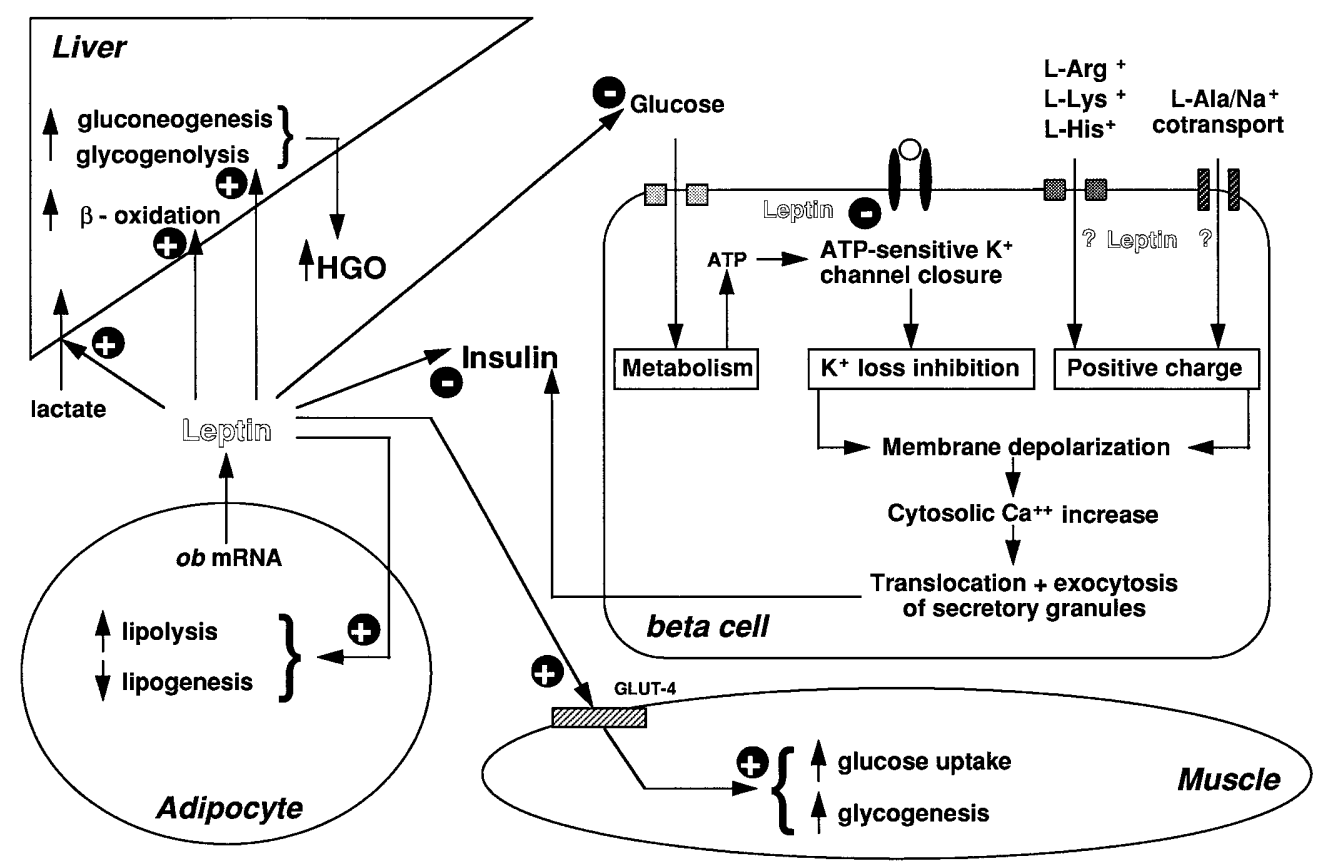

Fig.3. Descriptive physiologic view of the peripheral organs involved in the regulation of glucose metabolism by leptin and insulin. HGO, hepatic glucose output

cordance with data showing an up to two fold increase in GLUT4 expression in leptin-treated mice [83], which suggests that glucose uptake (and insulin sensitivity) is enhanced by leptin in the presence of normal concentrations of insulin and glucagon (Fig. 3).

Recently, leptin has been shown to exert a similar effect to that of insulin on glucose oxidation. Leptin seems to stimulate the activity of both pyruvate dehydrogenase and other key enzymes of the Krebs cycle [79]. It could, however, also be a consequence of an indirect leptin effect such as activation of the mitochondrial UCP. Mitochondria uncoupling reduces the intracellular ATP:ADP ratio, which activates pyruvate dehydrogenase and the enzymes of the Krebs cycle [84]. Leptin is known to up-regulate the expression of UCP-3 mRNA in skeletal muscle of rodents treated with intraperitoneal injections of leptin $[85,86]$. It can be speculated that leptin up-regulates expression of UCP-3 thus indirectly activating pyruvate dehydrogenase and the Krebs cycle.

In vivo studies using the euglycaemic hyperinsulinaemic clamp in rats have shown that an increase in plasma leptin enhances insulin's ability to inhibit hepatic glucose production but does not affect peripheral insulin action [87]. Furthermore, 2-deoxy-glucose uptake was not different between control and leptin-infused rats, which is in agreement with in vitro data showing no additive effect on either physiological or supraphysiological insulin stimulated 2-deoxy-glucose uptake and glycogen synthesis in soleus muscle [79]. Possibly under physiological circumstances, i.e. in the presence of insulin, the effects of leptin on muscle glucose metabolism are supplanted by those of insulin.

Glucose is transported and phosphorylated to produce glucose-6-phosphate in adipose cells and skeletal muscle. Glucose-6-phosphate is used mainly in glycogen synthesis and glycolysis. Approximately $1-3 \%$ of the incoming glucose is, however, converted to fructose-6-phosphate and enters the hexosamine biosynthetic pathway. This regulatory pathway is a cellular sensor of energy availability and mediates the effects of glucose on the expression of several gene products, including a rapid activation of the $o b$ gene [58]. Thus, evidence of inducible leptin expression in skeletal muscle through a nutrient-sensing pathway unveil the biochemical link between increased glucose availability and leptin secretion.

On the other hand, other researchers have presented evidence against a direct effect of leptin on glucose metabolism in skeletal muscle [62, 88-90]. No effects of short-term or long-term leptin exposure were observed on the rates of basal and insulin-stimulated 2-deoxy-glucose transport, glycogen synthesis, $\mathrm{CO}_{2}$ production and lactate release. Leptin neither influenced insulin-independent glucose metabolism nor did it affect insulin sensitivity or responsiveness in experiments designed to cover basal and partially as well as maximally insulin-stimulated conditions. Both the short and long OB-R isoforms are expressed in predominantly slow-twitch or fast-twitch muscles, which have metabolically diverse characteristics [91]. The lack of effect of leptin on glucose metabolism was independent of muscle fibre type and prevailing insulin concentration [88]. In addition, no qualitative 
differences have been observed in the pattern of response of OB-R mRNA expression of mainly oxidative or glycolytic muscles in the pre-prandial and postprandial state [91].

Differences in the experimental approach used to study the effects of leptin could underlie the diverse findings. Intact soleus muscle from recently weaned Wistar rats as well as slices of soleus muscle from adult Sprague-Dawley rats and $\mathrm{C}_{2} \mathrm{C}_{12}$ myotubes have been studied. Age-related differences in the response to leptin treatment were observed [92]. Species and strains of the animals, muscle extraction procedure and sources of leptin were also taken into account. In addition, native muscle tissue more closely resembles the physiological situation than myotube culture.

Skeletal muscle has an important role in NEFA and triacylglycerol clearance as well as in wholebody fatty acid oxidation. In intact muscle, leptin and insulin seem to have opposite effects on lipid metabolism, with leptin favouring lipid oxidation and insulin facilitating lipid storage in triacylglycerol [57, 77]. Leptin-induced changes in the partitioning of muscular fatty acids are consistent with data from whole-animal studies in which leptin appeared to promote fatty acid oxidation and decrease adipose tissue mass $[2,6,7]$. Thus, skeletal muscle could be considered critical in mediating leptin's effects on fuel homeostasis, weight regulation and adiposity. Leptin appears to attenuate the antioxidative lipogenic actions of insulin on muscle fatty acid metabolism without inhibiting insulin-stimulated glucose disposal. Both obesity and non-insulin-dependent diabetes mellitus are associated with decreased fatty acid oxidation and increased concentrations of muscle triacylglycerol and diacylglycerol [93, 94]. Thus, defects in cellular lipid metabolism could have a role in the development of muscle insulin resistance associated with obesity and leptin regarded as a possible regulator of peripheral glucose homeostasis.

\section{References}

1. Zhang Y, Proenca R, Maffei M, Barone M, Leopold L, Friedman JM (1994) Positional cloning of the mouse obese gene and its human homologue. Nature 372: 425-432

2. Pelleymounter MA, Cullen MJ, Baker MB et al. (1995) Effects of the obese gene product on body weight regulation in $o b / o b$ mice. Science 269: 540-543

3. Halaas JL, Gajiwala KS, Maffei M et al. (1995) Weight-reducing effects of the plasma protein encoded by the obese gene. Science 269: 543-546

4. Campfield LA, Smith FJ, Guisez Y, Devos R, Burn P (1995) Recombinant mouse OB protein: evidence for a peripheral signal linking adiposity and central neural networks. Science 269: 546-549

5. Tritos NA, Mantzoros CS (1997) Leptin: its role in obesity and beyond. Diabetologia 40: 1371-1379

6. Frühbeck G, Jebb SA, Prentice AM (1998) Leptin: physiology and pathophysiology. Clin Physiol 18: 399-419
7. Levin N, Nelson C, Gurney A, Vandlen R, de Sauvage F (1996) Decreased food intake does not completely account for adiposity reduction after $o b$ protein infusion. Proc Natl Acad Sci USA 93: 1726-1730

8. Hwa JJ, Fawzi AB, Graziano MP et al. (1997) Leptin increases energy expenditure and selectively promotes fat metabolism in ob/ob mice. Am J Physiol 272: R1204R1209

9. Shimabukuro M, Koyama K, Chen G et al. (1997) Direct antidiabetic effect of leptin through triglyceride depletion of tissues. Proc Natl Acad Sci USA 94: 4637-4641

10. Chen G, Koyama K, Yuan X et al. (1996) Disappearance of body fat in normal rats induced by adenovirus-mediated leptin gene therapy. Proc Natl Acad Sci USA 93: 14795-14799

11. Madej T, Boguski MS, Bryant SH (1995) Threading analysis suggests that the obese gene product may be a helical cytokine. FEBS Lett 373: 13-18

12. Chehab FF, Lim ME, Lu RH (1996) Correction of the sterility defect in homozygous obese female mice by treatment with the human recombinant leptin. Nat Genet 12: 318-320

13. Sierra-Honigmann MR, Nath AK, Murakami C et al. (1998) Biological action of leptin as an angiogenic factor. Science 281: 1683-1686

14. Cioffi JA, Shafer AW, Zupancic TJ et al. (1996) Novel B219/OB receptor isoforms: possible role of leptin in haematopoiesis and reproduction. Nat Med 2: 585-589

15. Lord GM, Matarese G, Howard JK, Baker RJ, Bloom SR, Lechler RI (1998) Leptin modulates the T-cell immune response and reverses starvation-induced immunosuppression. Nature 394: 897-901

16. Tartaglia LA (1997) The leptin receptor. J Biol Chem 272: 6093-6096

17. Trayhurn P, Hoggard N, Mercer JG, Rayner DV (1999) Leptin: fundamental aspects. Int J Obes 23[Suppl 1]: 22-28

18. Flatt PR (1997) The hormonal and neural control of endocrine pancreatic function. In: Pickup J, Williams G (eds) Textbook of Diabetes. 2nd edn. Vol 1. Blackwell Science Ltd., Oxford, pp 9.1-9.17

19. Koyama K, Chen G, Wang M-Y et al. (1997) Beta-cell function in normal rats made chronically hyperleptinaemic by adenovirus-leptin gene therapy. Diabetes 46: 1276-1280

20. Walder K, Lewandowski P, Morton G et al. (1999) Leptin resistance in a polygenic, hyperleptinaemic animal model of obesity and NIDDM: Psammomys obesus. Int J Obes 23 [Suppl 1]: 83-89

21. Ceddia RB, William WN Jr, Curi R (1998) Leptin increases glucose transport and utilization in skeletal muscle in vitro. Gen Pharmacol 31: 799-801

22. Ishizuka T, Ernsberger P, Liu S et al. (1998) Phenotypic consequences of a nonsense mutation in the leptin receptor gene (fak) in obese spontaneously hypertensive Koletsky rats (SHROB). J Nutr 128: 2299-2306

23. Kieffer TJ, Heller RS, Habener JF (1996) Leptin receptors expressed on pancreatic ß-cells. Biochem Biophys Res Commun 224: 522-527

24. Emilsson V, Liu Y-L, Cawthorne MA, Morton NM, Davenport M (1997) Expression of the functional leptin receptor mRNA in pancreatic islets and direct inhibitory action of leptin on insulin secretion. Diabetes 46: 313-316

25. Leclercq-Meyer V, Considine RV, Sener A, Malaisse WJ (1996) Do leptin receptors play a functional role in the endocrine pancreas? Biochem Biophys Res Commun 229: 794-798

26. Harvey J, McKenna F, Herson PS, Spanswick D, Ashford ML (1997) Leptin activates ATP-sensitive potassium chan- 
nels in the rat insulin secreting cell line, CRI-GI. J Physiol (Lond) 504: 527-535

27. Kieffer TJ, Heller RS, Leech CA, Holz GG, Habener JF (1997) Leptin suppression of insulin secretion by the activation of ATP-sensitive $\mathrm{K}^{+}$channels in pancreatic $\beta$-cells. Diabetes 46: 1087-1093

28. Spanswick D, Smith MA, Groppi VE, Logan SD, Ashford MLJ (1997) Leptin inhibits hypothalamic neurons by activation of ATP-sensitive potassium channels. Nature 390: 521-525

29. Lupi R, Marchetti P, Maffei M et al. (1999) Effects of acute or prolonged exposure to human leptin on isolated human islet function. Biochem Biophys Res Commun 256: 637-641

30. Wang M-Y, Koyama K, Shimabukuro M, Mangelsdorf D, Newgard CB, Unger RH (1998) Overexpression of leptin receptors in pancreatic islets of Zucker diabetic fatty rats restores GLUT-2, glucokinase and glucose-stimulated insulin secretion. Proc Natl Acad Sci USA 95: 11921-11926

31. Chen N-G, Swick AG, Romsos DR (1997) Leptin constrains acetylcholine-induced insulin secretion from pancreatic islets of $o b / o b$ mice. J Clin Invest 100: 1174-1179

32. Ookuma M, Ookuma K, York DA (1998) Effects of leptin on insulin secretion from isolated rat pancreatic islets. Diabetes 47: 219-223

33. Ishida K, Murakami T, Mizuno A, Iida M, Kuwajima M, Shima K (1997) Leptin suppresses basal insulin secretion from rat pancreatic islets. Regul Pept 70: 179-182

34. Koyama K, Chen G, Wang M-Yet al. (1997) Beta-cell function in normal rats made chronically hyperleptinaemic by adenovirus-leptin gene therapy. Diabetes 46: 1276-1280

35. Kulkarni RN, Wang Z-L, Wang R-M et al. (1997) Leptin rapidly suppresses insulin release from insulinoma cells, rat and human islets and, in vivo, in mice. J Clin Invest 100: 2729-2733

36. Pallett AL, Morton NM, Cawthorne MA, Emilsson V (1997) Leptin inhibits insulin secretion and reduces insulin mRNA levels in rat isolated pancreatic islets. Biochem Biophys Res Commun 238: 267-270

37. Poitout V, Rouault C, Guerre-Millo M, Briaud I, Reach G (1997) Inhibition of insulin secretion by leptin in normal rodent islets of Langerhans. Endocrinology 139: 822-826

38. Zhao AZ, Bornfeldt KE, Beavo JA (1998) Leptin inhibits insulin secretion by activation of phosphodiesterase 3B. J Clin Invest 102: 869-873

39. Seufert J, Kieffer TJ, Habener JF (1999) Leptin inhibits insulin gene transcription and reverses hyperinsulinaemia in leptin-deficient $o b / o b$ mice. Proc Natl Acad Sci USA 96: 674-679

40. Fehmann HC, Bode HP, Ebert T, Karl A, Göke B (1997) Interaction of GLP-1 and leptin at rat pancreatic B-cells: effects on insulin secretion and signal transduction. Horm Metab Res 29: 572-576

41. Seufert J, Kieffer TJ, Leech CA et al. (1999) Leptin suppression of insulin secretion and gene expression in human pancreatic islets: implications for the development of adipogenic diabetes mellitus. J Clin Endocrinol Metab 84: 670-676

42. Zhou Y-T, Shimabukuro M, Koyama K et al. (1997) Induction by leptin of uncoupling protein-2 and enzymes of fatty acid oxidation. Proc Natl Acad Sci USA 94: 6386-6390

43. Zhou Y-T, Shimabukuro M, Lee Y et al. (1998) Enhanced de novo lipogenesis in the leptin-unresponsive pancreatic islets of prediabetic Zucker diabetic fatty rats. Role in the pathogenesis of lipotoxic diabetes. Diabetes 47: 1904-1908

44. Jansson L (1994) The regulation of pancreatic islet blood flow. Diabetes Metab Rev 10: 407-416
45. Carlsson P-O, Andersson A, Jansson L (1998) Influence of age, hyperglycemia, leptin, and NPY on islet blood flow in obese-hyperglycemic mice. Am J Physiol 275: E594-E601

46. Carlsson P-O, Andersson A, Jansson L (1996) Pancreatic islet blood flow in normal and obese-hyperglycemic (ob/ ob) mice. Am J Physiol 271: E990-E995

47. Rossetti L, Massillon D, Barzilai N et al. (1997) Short term effects of leptin on hepatic gluconeogenesis and in vivo insulin action. J Biol Chem 272: 27758-27763

48. Liu L, Karkanias GB, Morales JC et al. (1999) Intracerebroventricular leptin regulates hepatic but not peripheral glucose fluxes. J Biol Chem 273: 31160-31167

49. Nemecz M, Preininger K, Englisch R et al. (1999) Acute effect of leptin on hepatic glycogenolysis and gluconeogenesis in perfused rat liver. Hepatology 29: 166-172

50. Cohen B, Novick D, Rubinstein M (1996) Modulation of insulin activities by leptin. Science 274: 1185-1188

51. Wang Y, Kuropatwinski KK, White DW et al. (1997) Leptin receptor action in hepatic cells. J Biol Chem 272: 16216-16223

52. Takahashi Y, Okimura Y, Ishikazu M et al. (1997) Leptin induces mitogen-activated protein kinase-dependent proliferation of 3H10T1/2 cells. J Biol Chem 272: 12897-12900

53. Kamohara S, Burcelin R, Halaas JL, Friedman JM, Charron MJ (1997) Acute stimulation of glucose metabolism in mice by leptin treatment. Nature 389: 374-377

54. Roden M, Perseghin G, Petersen KF et al. (1996) The roles of insulin and glucagon in the regulation of hepatic glycogen synthesis and turnover in humans. J Clin Invest 97: 642-648

55. Bai Y, Zhang S, Kim K-S, Lee J-K, Kim K-H (1996) Obese gene expression alters the ability of $30 \mathrm{~A} 5$ preadipocytes to respond to lipogenic hormones. J Biol Chem 271: 13939-13942

56. Müller G, Ertl J, Gerl M, Preibisch G (1997) Leptin impairs metabolic actions of insulin in isolated rat adipocytes. $\mathrm{J}$ Biol Chem 272: 10585-10593

57. Muoio DM, Dohn GL, Fiedorek FT Jr, Tapscott EB, Coleman RA (1997) Leptin directly alters lipid partitioning in skeletal muscle. Diabetes 46: 1360-1363

58. Wang J, Liu R, Hawkins M, Barzilai N, Rossetti L (1998) A nutrient-sensing pathway regulates leptin gene expression in muscle and fat. Nature 393: 684-688

59. Schwartz MW, Baskin DG, Bukowski TR et al. (1996) Specificity of leptin action on elevated blood glucose levels and hypothalamic neuropeptide Y gene expression in $o b /$ $o b$ mice. Diabetes 45: 531-535

60. Sivitz WI, Walsh SA, Morgan DA, Thomas MJ, Haynes WG (1997) Effects of leptin on insulin sensitivity in normal rats. Endocrinology 138: 3395-3401

61. Barzilai N, Massillon D, Vuguin P, Hawkins M, Rossetti L (1997) Leptin selectively decreases visceral adiposity and enhances insulin action. J Clin Invest 100: 3105-3110

62. Burcelin R, Kamohara S, Li J, Tannenbaum GS, Charron MJ, Friedman JM (1999) Acute intravenous leptin infusion increases glucose turnover but not skeletal muscle glucose uptake in ob/ob mice. Diabetes 48: 1264-1269

63. Rohner-Jeanrenaud F, Proietto J, Ionescu E, Jeanrenaud B (1986) Mechanism of abnormal oral glucose tolerance of genetically obese $(\mathrm{fa} / \mathrm{fa})$ rats. Diabetes 35: 1350-1355

64. Sanchez-Gutierrez J, Sanchez-Arias J, Lechuga CG, Valle JC, Samper B, Feliu JE (1994) Decreased responsiveness of basal gluconeogenesis to insulin action in hepatocytes isolated from genetically obese ( $f a / f a)$ Zucker rats. Endocrinology 134: 1868-1873

65. Flier JS (1997) Leptin expression and action: new experimental paradigms. Proc Natl Acad Sci USA 94: 4242-4245 
66. Felig P, Wahren J, Hendler R, Brudin T (1974) Splanchnic glucose and amino acid metabolism in obesity. $\mathrm{J}$ Clin Invest 53: $582-590$

67. Morton NM, Emilsson V, Liu Y-L, Cawthorne MA (1998) Leptin action in intestinal cells. J Biol Chem 273: 26194-26201

68. Lostao MP, Urdaneta E, Martínez-Ansó E, Barber A, Martínez JA (1998) Presence of leptin receptors in rat small intestine and leptin effect on sugar absorption. FEBS Lett 423: 302-306

69. Bado A, Levasseur S, Attoub S et al. (1998) The stomach is a source of leptin. Nature 394: 790-793

70. Coleman RA, Herrmann TS (1999) Nutritional regulation of leptin in humans. Diabetologia 42: 639-646

71. Barrachina MD, Martinez V, Wang L, Wei JY, Taché Y (1997) Synergistic interaction between leptin and cholecystokinin to reduce short-term food intake in lean mice. Proc Natl Acad Sci USA 94: 10455-10460

72. Matson CA, Wiater MF, Kuijper JL, Weigle DS (1997) Synergy between leptin and cholecystokinin (CCK) to control daily caloric intake. Peptides 18: 1275-1278

73. Matson CA, Ritter RC (1999) Long-term CCK-leptin synergy suggests a role for CCK in the regulation of body weight. Am J Physiol 276: R1038-R1045

74. Barrachina MD, Martinez V, Wei JY, Taché Y (1997) Leptin-induced decrease in food intake is not associated with changes in gastric emptying in lean mice. Am J Physiol 272: R1007-R1011

75. Emond M, Schwartz GJ, Ladenheim EE, Moran TH (1999) Central leptin modulates behavioural and neural responsivity to CCK. Am J Physiol 276: R1545-R1549

76. Wang YH, Taché Y, Sheibel AB, Go VLW, Wei JY (1997) Two types of leptin-responsive gastric vagal afferent terminals: an in vitro single-unit study in rats. Am J Physiol 273: R833-R837

77. Muoio DM, Dohm GL, Tapscott EB, Coleman RA (1999) Leptin opposes insulin's effects on fatty acid partitioning in muscles isolated from obese $o b / o b$ mice. Am J Physiol 276: E913-E921

78. Wang J-L, Chinookoswong N, Scully S, Qi M, Shi Z-Q (1999) Differential effects of leptin in regulation of tissue glucose utilization in vivo. Endocrinology 140: 2117-2124

79. Ceddia RB, William WN Jr, Curi R (1999) Comparing effects of leptin and insulin on glucose metabolism in skeletal muscle: evidence for an effect of leptin on glucose uptake and decarboxylation. Int J Obes 23: 75-82

80. Berti L, Kellerer M, Capp E, Häring HU (1997) Leptin stimulates glucose transport and glycogen synthesis in $\mathrm{C}_{2} \mathrm{C}_{12}$ myotubes: evidence for a PI3-kinase mediated effect. Diabetologia 1997: 606-609

81. Kellerer M, Koch ML, Metzinger E, Mushak J, Capp E, Häring HU (1997) Leptin activates PI3-kinase in $\mathrm{C}_{2} \mathrm{C}_{12}$ myotubes via janus kinase-2 (JAK-2) and insulin receptor substrate-2 (IRS-2) dependent pathways. Diabetologia 40: $1358-1362$

82. Okada T, Kawano Y, Sakakibara T, Hazeki O, Ui M (1994) Essential role of phosphatidylinositol 3-kinase in insulininduced glucose transport and antilipolysis in rat adipocytes. Studies with a selective inhibitor wortmannin. J Biol Chem 269: 3568-3573

83. Sarmiento U, Benson B, Kaufman S et al. (1997) Morphologic and molecular changes induced by recombinant human leptin in white and brown adipose tissues of C57BL/ 6 mice. Lab Invest 77: 243-256

84. Curi R, Newsholme E (1989) The effect of adenosine nucleotides on the rate and fate of glutamine utilization by incubated mitochondria isolated from rat mesenteric lymph nodes. Mol Cell Biochem 86: 71-76

85. Gong DW, He Y, Karas M, Reitman M (1997) Uncoupling protein-3 is a mediator of thermogenesis regulated by thyroid hormone, B3-adrenergic agonists, and leptin. J Biol Chem 272: 24129-24132

86. Gómez-Ambrosi J, Frühbeck G, Martínez JA (1999) Leptin, but not a $\beta_{3}$-adrenergic agonist, upregulates muscle uncoupling-3 messenger RNA expression: short-term thermogenic interactions. Cell Mol Life Sci 55: 992-997

87. Rossetti L, Massillon D, Barzilai N et al. (1997) Short term effects of leptin on hepatic gluconeogenesis and in vivo insulin action. J Biol Chem 272: 27758-27763

88. Fürsinn C, Brunmair B, Furtmüller R, Roden M, Englisch R, Waldhäusl W (1998) Failure of leptin to affect basal and insulin-stimulated glucose metabolism of rat skeletal muscle in vitro. Diabetologia 41: 524-529

89. Zierath JR, Frevert EU, Ryder JW, Berggren P-O, Kahn BB (1998) Evidence against a direct effect of leptin on glucose transport in skeletal muscle and adipocytes. Diabetes 47: $1-4$

90. Ranganathan S, Ciaraldi TP, Henry RR, Mudaliar S, Kern PA (1998) Lack of effect of leptin on glucose transport, lipoprotein lipase, and insulin action in adipose and muscle cells. Endocrinology 139: 2509-2513

91. Frühbeck G, Gómez-Ambrosi J, Martínez JA (1999) Preand postprandial expression of the leptin receptor splice variants $\mathrm{OB}-\mathrm{Ra}$ and $\mathrm{OB}-\mathrm{Rb}$ in murine peripheral tissues. Physiol Res 48: 189-195

92. Frühbeck G, García-Granero M, Martínez JA (1998) Agerelated differences in the thermogenic and ponderal effects following the administration of fragment peptides from the rat $o b$ protein. Regul Pept 73: 83-87

93. Coldberg SR, Simoneau JA, Thaete FL, Kelley DE (1995) Skeletal muscle utilization of free fatty acids in women with visceral obesity. J Clin Invest 95: 1846-1853

94. Phillips DIW, Caddy S, Iiic V et al. (1996) Intramuscular triglyceride and muscle insulin sensitivity: evidence for a relationship in nondiabetic subjects. Metabolism 45: 947-950 